\title{
The economics of tackling climate change
}

\section{Don't leave health benefits out of the equation}

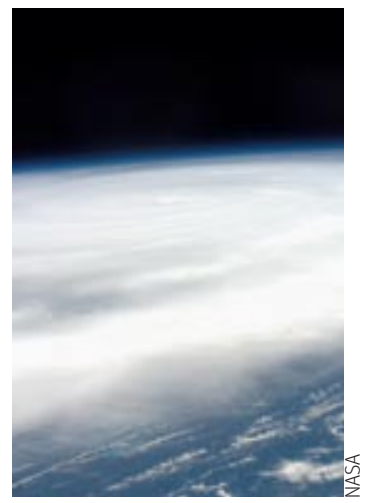

OBSERVATIONS, p 189 ANALYSIS, p 191

\section{Ian Roberts professor of} epidemiology and public health, London School of Hygiene and Tropical Medicine, London, UK

lan.Roberts@lshtm.ac.uk

Competing interests: None declared.

Provenance and peer review: Commissioned based on an idea from the Climate and Health Council; not externally peer reviewed.

BMJ 2008;336:165-6 doi: 10.1136/bmj.39468.596262.80
Tony Blair welcomed the publication of the Stern review on the economics of climate change calling it a wake up call to the world. ${ }^{1}$ Its message was clear. The costs of taking action to stabilise the climate will be high but much less than the costs of inaction. Delay would be dangerous. Action is needed now. The review also exposed the economic cause of climate change. Climate change is market failure on the greatest scale the world has ever seen. ${ }^{1}$

Markets fail to provide the right quantity of goods and services when important costs are left out of our private economic decision making. In general, the extent to which people engage in activities that result in the emission of greenhouse gases depends on the cost of those activities. For example, when deciding whether to travel by car we might consider the cost of the time, petrol, parking, and wear and tear on the vehicle. Londoners might include the congestion charge, but few people would take into account the costs to the world and future generations of the emissions that their journey will produce. Costs on others that do not (without public action) enter into the private arithmetic of how we allocate resources are called externalities and are the economic basis of one of the greatest threats humanity has ever faced.

While economists have been grappling with the resource implications of policies to tackle climate change, the public health implications of these policies have also come under scrutiny. ${ }^{2}$ The message this time is that they present unrivalled opportunities for improving public health. Policies that reduce greenhouse gas emissions could also substantially reduce obesity, diabetes, heart disease, cancer, road deaths and injuries, and air pollution. ${ }^{2}$

Take food production for instance, which results in substantial greenhouse emissions, similar in magnitude to those from transport or industry. ${ }^{1}$ Livestock rearing for meat and dairy produce is a major source of emissions, including methane from enteric fermentation and carbon dioxide as a result of land clearance for cattle farming. ${ }^{3}$ Polices that internalise the environmental costs of livestock production would reduce the consumption of animal products. This would help stabilise the climate, but would also-by reducing the amount of saturated fat and meat in the diet-reduce the incidence of cardiovascular disease and bowel cancer. ${ }^{3}$ Similar policies on other foods might decrease the consumption of the carbon intensive fats and refined sugars that are helping to fuel the obesity pandemic. ${ }^{4}$

The transition to a low carbon transport system that involved more walking and cycling would substantially benefit health. ${ }^{5}$ Road traffic crashes account for 1.2 million deaths worldwide each year and 10 times as many serious injuries. Their incidence is a function of the use of fossil fuels by the transport sector. ${ }^{6}$ After all, the kinetic energy that breaks bones and tears soft tissues comes from the chemical energy stored in the fuel tank, the burning of which emits carbon dioxide. Death rates for pedestrians and cyclists exhibit steep social gradients, and reducing traffic volumes and speeds would have important equity implications. ${ }^{7}$ Urban air pollution-much of which is related to transport-causes a further 800000 premature deaths each year. ${ }^{5}$ Walking, cycling, or using public transport instead of travelling by car would reduce the use of energy from fossil fuels; it would also reduce traffic injuries and air pollution. By increasing physical activity it would tackle the output side of the personal energy balance equation, again with implications for obesity.

Improvements in the efficiency of home energy will reduce mortality and morbidity from the extremes of heat and cold and reduce the vulnerability of the poor to fluctuations in the price of energy. ${ }^{8}$ Greater use of renewable energy sources will also reduce urban air pollution. In generating electricity, the energy sources with the highest carbon dioxide emission profiles also have the greatest effect on air pollution and the incidence of occupational injuries. ${ }^{9}$

Providing access to clean energy for the 2.4 billion people who use biomass fuels for cooking would reduce the burden of mortality and morbidity from indoor air pollution, and universal access to clean electricity could initiate a tidal wave of human creativity and accelerate the pace of human development. ${ }^{2}{ }^{2}$

Like Tony Blair, Gordon Brown also welcomed the Stern review calling it "the most comprehensive analysis yet" and commenting that "above all environmental policy is economic policy." Stern acknowledged that any positive effects of tackling climate change over and above those detailed in his review would strengthen the economic argument for stabilising the climate. The full extent of health benefits is only now coming to light.

Climate change, a globally important externality, is at least partly the result of leaving environmental impact out of economic decision making. To leave out health when considering the benefits of policies that tackle climate change would be a second serious omission. Environmental policy is economic policy. It is also health policy. Economists and health professionals must work together to ensure that the effects of environmental 
policies on health and development are quantified and included in the economic models that inform our collective response to the threat from climate change.

It would not be the first time that environmental policy had substantial benefits for health. Two hundred years ago the streets of London were awash with sewage. In 1858 the smell from the Thames was so strong that MPs declared the House of Commons "unusable." ${ }^{11}$ Infectious disease was a deadly scourge, but it was the "great stink" of 1858 that helped secure the funds needed to sort out London's sewage. Policy on sewage did more to improve the health of Londoners than any health policy that century. Indeed, in a recent $B M J$ poll, sanitation was voted the greatest medical advance in the past 166 years. ${ }^{12}$ Could tackling climate be the next great medical advance?

1 Stern N. The economics of climate change: the Stern review. Cambridge: Cambridge University Press, 2007.

2 Haines A, Smith KR, Anderson D, Epstein P, McMichael A, Roberts I, et al. Policies for accelerating access to clean energy, improving health, advancing development, and mitigating climate change. Lancet 2007;370:66-83.

3 McMichael AJ, Powles JW, Butler CD, Uauy R. Food, livestock production, energy, climate change, and health. Lancet 2007;370:1253-63.

4 Roberts I. Comment and analysis: say no to global guzzling. New Scientist 2007:309:21.

5 Woodcock J, Banister D, Edwards P, Prentice AM, Roberts I. Energy and transport. Lancet 2007;370:1078-88.

6 Roberts I, Arnold E. Policy at the crossroads: climate change and injury control. Inj Prev 2007;13:222-3.

7 Edwards P, Roberts I, Green J, Lutchmum S. Deaths from injury in children and employment status in family: analysis of trends in class specific death rates. BMJ 2006;333:119.

8 Wilkinson P, Smith KR, Beevers S, Tonne C, Oreszczyn T. Energy, energy efficiency, and the built environment. Lancet 2007;370:1175-87.

9 Markandya A, Wilkinson P. Electricity generation and health. Lancet 2007;370:979-90.

10 Wilkinson P, Smith KR, Joffe M, Haines A. A global perspective on energy: health effects and injustices. Lancet 2007:370:965-78.

11 Cook GC. Construction of London's Victorian sewers: the vital role of Joseph Bazalgette. Postgrad Med I 2001;77:802-4

12 Mackenbach JP. Sanitation: pragmatism works. BMJ 2007;334:S17; doi: $10.1136 /$ bmj.39044.508646.94

\section{Aspirin resistance in cardiovascular disease}

\section{Carries a worse prognosis, but may indicate pre-existing higher risk}

\section{RESEARCH, p 195}

Giuseppe Biondi-Zoccai assistant professor in cardiology, Division of Cardiology, University of Turin, 10126 Turin, Italy

gbiondizoccai@gmail.com

Marzia Lotrionte consultant cardiologist, Institute of Cardiology, Catholic University, 00136 Rome, Italy Competing interests: GB-Z has received lecture fees from BristolMyers Squibb.

Provenance and peer review: Commissioned; not externally peer reviewed.

BMJ 2008;336:166-7

doi: 10.1136/bmj.39405.635498.80
Aspirin has clear benefits in cardiovascular disease. It reduces total mortality, cardiovascular mortality, and cardiovascular morbidity in people with cardiovascular disease or those at high risk of the disease; it is also cheap, relatively safe, and easy to use. ${ }^{1}$ So why does aspirin fail to work in some people who take it as prescribed? Research on this clinical "resistance" to aspirin has tried to assess whether the effect on the in vitro activation of platelets depends only on the dose and type of antithrombotic agent given, or whether some people respond poorly ("resist") to a specific drug, as some people do to specific antibiotics. In the accompanying systematic review, Krasopoulos and colleagues assess whether resistance to aspirin is related to cardiovascular outcomes in people with cardiovascular disease. ${ }^{2}$

To date, most research has focused on whether aspirin resistance really exists, whether antiplatelet resistance is specific to certain agents or classes of drug, ${ }^{3}$ and whether resistance carries a worse prognosis. Firstly, no accepted gold standard test to define aspirin resistance is available. ${ }^{4}$ This and other epidemiological considerations have led some authors to argue that what has been dubbed resistance is just part of normal (Gaussian) variability in pharmacokinetics and pharmacodynamics. Others admit that aspirin resistance exists but are doubtful about its prognostic importance..$^{5}$ They think that a lack of response to aspirin could just be a proxy marker for more advanced pre-existing disease or less controlled traditional risk factors.

Krasopoulos and colleagues review analysed data from 20 studies and 2930 patients and found resistance to aspirin in $28 \%$ of people. Resistance was significantly more common in women and those with renal failure and was associated with a statistically and clinically significant increase in the risk of death or adverse cardio- vascular events, at least in univariate analysis. However, they found no association between the dose of aspirin or concomitant use of other antiplatelet agents and adverse events. The review has some limitations including use of fixed effect methods and lack of pooled multivariable adjusted estimates. A similar review recently came to the same conclusions, however, confirming the external validity of Krasopoulos and colleagues' review. ${ }^{6}$

Despite this work several questions remain. We don't know whether aspirin resistance is a true abnormal response or whether it reflects normal variability in drug activity. We also aren't clear whether aspirin resistance has a negative prognostic effect independent of more traditional risk factors, such as diabetes or obesity. ${ }^{5}$ If aspirin resistance is an abnormal response that results in worse prognosis then what can clinicians do? We suggest that when aspirin resistance is suspected patients should be screened using available tests. Management of patients with aspirin resistance should include a comprehensive appraisal of thrombotic and bleeding risks, the likelihood of non-adherence to treatment, and access to other antiplatelet agents. On the basis of this assessment, several strategies can then be proposed. These include adding another antiplatelet agent (for people at high thrombotic risk and low bleeding risk), substituting aspirin with the more effective clopidogrel (for people at intermediate thrombotic risk and low bleeding risk), increasing the dose of aspirin (for example, to $325 \mathrm{mg} /$ day in people at mildly increased thrombotic risk and low to intermediate bleeding risk), or continuing with the same antiplatelet regimen (for everyone at high bleeding risk).

The problem in finding truly scientific answers to the effectiveness of these strategies lies in the lack of randomised controlled clinical trials. This will 
probably change, however, as results from trials such as TREND-AR (tirofiban evaluation of surrogate endpoints in prevention of ischaemic complications during percutaneous interventions in patients with coronary disease and aspirin resistance) become available. This trial will randomise patients undergoing percutaneous coronary intervention who have documented aspirin resistance to a combination of clopidogrel, aspirin, heparin, and tirofiban (a potent antiplatelet agent) or clopidogrel, aspirin, and heparin. This trial, among others, will show whether aspirin resistance is just a non-modifiable risk factor (like age or sex) or whether more aggressive antithrombotic regimens are beneficial in patients with aspirin resistance.

Conducting more clinical trials will help fill in the gaps, but another potential reason exists for the interest in aspirin resistance. Drug companies may be keen to downgrade aspirin from its leading role as an effective drug in cardiovascular disease so that they can substitute it with much more expensive but marginally more effective alternatives.

1 Antithrombotic Trialists' Collaboration. Collaborative meta-analysis of randomised trials of antiplatelet therapy for prevention of death, myocardial infarction, and stroke in high risk patients. $B M$ J 2002;324:71-86

2 Krasopoulos G, Brister SJ, Beattie WS, Buchanan MR. Aspirin "resistance" and risk of cardiovascular morbidity: systematic review and meta-analysis. BM/ 2008 doi: 10.1136/bmj.39430.529549.BE.

3 Campo G, Valgimigli M, Gemmati D, Percoco G, Catozzi L, Frangione A, et al. Poor responsiveness to clopidogrel: drug-specific or class-effect mechanism? Evidence from a clopidogrel-to-ticlopidine crossover study. J Am Coll Cardiol 2007;50:1132-7.

4 Lordkipanidzé M, Pharand C, Schampaert E, Turgeon J, Palisaitis DA, Diodati JG. A comparison of six major platelet function tests to determine the prevalence of aspirin resistance in patients with stable coronary artery disease. Eur Heart J 2007; 28:1702-8.

5 Barnes GD, Li J, Kline-Rogers E, Vedre A, Armstrong DF, Froehlich JB, et al. Dual antiplatelet agent failure: a new syndrome or clinical nonentity? Am Heart J 2007;154:732-5.

6 Snoep JD, Hovens MM, Eikenboom JC, van der Bom JG, Huisman MV. Association of laboratory-defined aspirin resistance with a higher risk of recurrent cardiovascular events: a systematic review and metaanalysis. Arch Intern Med 2007;167:1593-9.

\section{Cannabinoids for chronic pain}

\section{Are effective but research is needed to decide who benefits most}

\section{RESEARCH, p 199}

\section{Steven P Cohen associate}

professor of anaesthesiology, Pain Management Division, Department of Anesthesiology and Critical Care Medicine, Johns Hopkins School of Medicine, Baltimore, MD 21205, USA, Department of Surgery, Walter Reed Army Medical Center, Washington, DC 21205, USA

scohen40@jhmi.edu

Competing interests: None declared.

Provenance and peer review: Commissioned; not externally peer reviewed.

BMJ 2008;336:167-8 doi: 10.1136/bmi.39434.444583.80
Cannabis has been cultivated as an elixir for pain since as far back as 2000 years BC. Amid increasing reports of psychosis, addiction, and other adverse effects the therapeutic use of smoked cannabis in the United States waned in the late 1930s, as a result of the Marihuana Tax Act and subsequent legislative measures, which posed nearly insurmountable obstacles for doctors. The past decade has, however, seen a resurgence in the interest in cannabinoids for alleviating pain, with the identification of at least two subtypes of cannabinoid receptors, and myriad clinical studies examining the effectiveness of tetrahydrocannabinol derivatives for acute pain, pain caused by chronic non-malignant disease, and pain from cancer. Evidence of the effectiveness of cannabinoids is strong for treating cancer, central pain, and spasticity related pain; the evidence is mixed for treating acute pain and weak for treating peripheral neuropathic pain.

In the accompanying paper, Frank and colleagues report the results of a randomised crossover controlled trial comparing the effectiveness of dihydrocodeine with the synthetic cannabinoid nabilone. ${ }^{1}$ The trial studied 96 patients with diverse neuropathic pain conditions.

The authors found that the mean visual analogue score at six weeks was $6.0 \mathrm{~mm}$ greater in people taking nabilone than in those taking dihydrocodeine $(95 \%$ confidence interval 10.5 to 1.4 ) for the available case analysis and $5.6 \mathrm{~mm}$ (10.3 to 0.8$)$ greater for the per protocol analysis. Although outcomes were not tabulated by diagnosis, only a few patients had central or spasticity related pain, the two pain conditions most responsive to treatment with cannabinoids. Almost half of the participants had post-traumatic pain or postsurgical pain, which often have multiple pain generators, a high prevalence of underlying psychopathology, and are difficult to treat.

These results are consistent with the literature on opioids and cannabinoids. Neuropathic pain was once believed to be refractory to opioids, but there is now indisputable evidence that it is responsive to opioids, albeit at higher doses than those used to treat nociceptive pain. ${ }^{2}$ In contrast, the evidence supporting cannabinoids for peripheral neuropathic pain and other chronic non-malignant pain disorders, while generally positive, is less strong and mostly confined to other synthetic analogues. ${ }^{345}$ Most people in Frank and colleagues' study had peripheral neuropathic pain.

Before embarking on large scale trials designed to establish who will benefit most from an intervention, investigators should first ensure that trials demonstrate internal validity because failure to do so threatens to undermine the very concept of any new treatment. Even if a subgroup of patients might have benefited from nabilone, the current study design was not powered to identify them.

So how should we interpret these results and put them into practice? Given the poor analgesic effect and the high incidence of adverse effects (more than $80 \%$ of participants reported tiredness, more than $50 \%$ reported sleeplessness and sickness, and more than 25\% reported tingling or feeling strange) seen in this and other studies, cannabinoids should not be used as first line agents in patients who present with uncategorised pain. Yet previous trials have shown that a small subset of patients with neuropathic pain and other chronic pain disorders may benefit from treatment with cannabinoids. ${ }^{3456}$ The most compelling evidence for the effectiveness of cannabinoids is in the relief of pain associated with multiple sclerosis 
and, to a lesser extent, other central pain syndromes. ${ }^{78}$ So why is there a discrepancy?

One key difference between the current study and studies with positive findings ${ }^{5678}$ is that Frank and colleagues used allodynia (which signifies evoked pain) and sympathetic dysfunction as inclusion criteria. Collectively, these signs are experienced by only a small subset of patients with chronic pain. In the current era, in which treatment of pain is ideally based on mechanism(s) of pain, pharmacotherapy should preferentially target specific pain generators. ${ }^{9}$ In multiple sclerosis, the condition with the strongest evidence for the effectiveness of cannabinoids, the most common manifestations of pain are continuous or spontaneous dysaesthesias, which are mechanistically different from allodynia. ${ }^{10}$ In addition, the evidence to support a sympathetic component in multiple sclerosis is scant.

Another potential flaw in the current study is that it assessed outcomes after only six weeks, which is too short a time frame to detect the low but clinically significant risk of adverse psychiatric effects such as psychosis, depression, cognitive deficits, and addiction. ${ }^{4}$ Similarly, short term reductions in pain scores do not necessarily translate into longstanding improvements in pain, functional capacity, and psychological wellbeing. Future trials evaluating treatment with cannabinoids might consider using risk assessment tools, like those used for opioids. ${ }^{11}$

Finally, there is the problem of the prohibition surrounding the medicinal use of cannabinoids. The therapeutic use of cannabinoids is about 50 years behind that of opioids, and the associated stigma poses a considerable barrier to research and development. ${ }^{12}$ Yet history tells us that the line dividing what is and isn't socially acceptable behaviour is often arbitrary and inseparable from the cultural-political context. Not so long ago, blood letting and the curative use of heavy metals were considered state of the art medical care. Although many such practices have been abandoned, others remain that do more harm than good.
Strong evidence supports the use of cannabinoids for chronic pain, but more research is needed to determine which diagnoses, pain characteristics, and clinical variables are most amenable to treatment; the long term effectiveness of these drugs; optimal drug selection and dosages; the risk-benefit ratio of combining cannabinoids with other drugs; and how adverse effects can be minimised. This research can occur only in a political climate conducive to the continued use and investigation of cannabinoids to alleviate pain and suffering.

1 Frank B, Serpell MG, Hughes J, Matthews JN, Kapur D. Comparison of analgesic effects and patient tolerability of nabilone and dihydrocodeine for chronic neuropathic pain: randomised, crossover, double blind study. BMJ 2008 10.1136/bmj.39429.619653.80.

2 Benedetti F, Vighetti S, Amanzio M, Casadio C, Oliaro A, Bergamasco $B$, et al. Dose-response relationship of opioids in nociceptive and neuropathic postoperative pain. Pain 1998;74:205-11.

3 Campbell FA, Tramer MR, Carroll D, Reynolds JM, Moore A, McQuay HJ. Are cannabinoids an effective and safe treatment option in the management of pain? A qualitative systematic review. BMJ 2001;323:13-6.

4 Rice AS, Lever I, Zarnegar R. Cannabinoids and analgesia, with special reference to neuropathic pain. In: McQuay HJ, Kalso E, Moore RA, eds. Systematic reviews in pain research: methodology refined. Seattle: IASP Press, 2007:233-46.

5 Abrams DI, Jay CA, Shade SB, Vizoso H, Reda H, Press S, et al. Cannabis in painful HIV-associated sensory neuropathy. A randomized placebocontrolled trial. Neurology 2007;68:515-21.

6 Notcutt W, Price M, Miller R, Newport S, Phillips C, Simmons S, Sansom C. Initial experiences with medicinal extracts of cannabis for chronic pain: results from 34 "N of 1" studies. Anaesthesia 2004;59:440-52.

7 Svendsen KB, Jensen TS, Bach FW. Does the cannabinoid dronabinol reduce central pain in multiple sclerosis? Randomised double blind placebo controlled trial. BMJ 2004; 329:253.

8 Zajicek J, Fox P, Sanders H, Wright D, Vickery J, Nunn A, Thompson A; UKMS Research Group. Cannabinoids for treatment of spasticity and other symptoms related to multiple sclerosis (CAMS study): multicentre randomised placebo-controlled study. Lancet 2003;362:1517-26.

9 Cohen SP, Verdolin MH, Chang AS, Kurihara C, Morlando BJ, Mao J. The IV ketamine test predicts subsequent response to an oral dextromethorphan treatment regimen in fibromyalgia patients. J Pain 2006;7:391-8.

10 O'Connor AB, Schwid SR, Herrmann DN, Markman JD, Dworkin RH. Pain associated with multiple sclerosis: systematic review and proposed classification. Pain 2007 Online first 8 October 2007.

11 Webster LR, Webster RM. Predicting aberrant behaviors in opioid treated patients: preliminary validation of the opioid risk tool. Pain Med 2005;6:432-42.

12 Zimmerman B, Bayer R, Crumpacker N. Is marijuana the right medicine foryou? A factual guide to the medical uses of marijuana. New Canaan, CT: Keats Publishing, 1998.

\section{Costs of treating malaria according to test results} Improving diagnostic tests can reduce costs if adherence to results is improved

\section{RESEARCH, p 202}

Zeno Bisoffi head of the centre for tropical diseases, S Cuore Hospital, 37024 Negrar, Verona, Italy zeno.bisoffi@sacrocuore.it

Jef Van den Ende head of the department of clinical sciences, Institute of Tropical Medicine, Nationalestraat 155-B-2000 Antwerp, Belgium Competing interests: None declared.

Provenance and peer review: Commissioned; not externally peer reviewed.

BMJ 2008;336:168-9 doi: 10.1136/bmj.39401.486655.80
In the accompanying study, Lubell and colleagues assess the effect of clinicians' adherence to the results of a rapid diagnostic test or microscopy on the overall costs of the management of malaria in Tanzania. ${ }^{1}$

In recent years, most treatment policies for malaria in Africa have shifted to artemisinin combination treatments, which are highly effective but more expensive than older regimens. To avoid over prescription, current guidelines recommend that the diagnosis should be confirmed with a laboratory test before treatment. Immunochromatographic tests for malaria allow diagnosis to be made even in health settings that lack laboratory facilities. Economic models and decision making models support the use of these tests. ${ }^{2-4} \mathrm{How}^{-}$ ever, models generally assume that clinicians or nurse practitioners fully adhere to the test result when deciding how to manage the patient. But evidence proves the opposite-clinicians are likely to treat people for malaria even after negative results from rapid diagnostic tests or microscopy. ${ }^{5}$ In a randomised controlled trial in Burkina Faso we recently found (data not yet published) that more than $80 \%$ of febrile patients with a negative test result were treated for malaria. ${ }^{7}$ Economic evaluations that fail to take into account what clinicians actually do in practice are therefore merely speculative.

Through a cost-benefit analysis based on a decision tree model, Lubell and colleagues show that-at low 
to moderate prevalence of malaria infection in febrile patients-clinician's adherence to the test result is a key factor in determining whether a diagnostic strategy is beneficial or not. This is true for rapid diagnostic tests even at higher levels of prevalence (up to 70\%). For microscopy, however, they observed a paradoxical effect-because sensitivity was poor (73\% v 93\% for rapid diagnostic tests), high adherence means that more patients with malaria are not treated, which increases mortality and related costs. At very high prevalence, presumptive treatment remains the preferred option.

The novel aspect of this paper is the formal incorporation of adherence into a model that could be used for policy decisions. Both the non-adherence of patients to their prescribed drugs and the nonadherence of clinicians to guidelines have been documented, even in areas such as cardiovascular medicine where robust evidence exists. ${ }^{8}$ Policy makers should take the importance of adherence seriously, and clinical guidelines should avoid ambiguous messages that may raise doubts about the reliability of a test, ${ }^{9}$ such as, if the test result is negative don't treat for malaria, unless clinical suspicion is high. Clinicians should realise that if the result of a test is not going to influence their decision, then it is simply a waste of money to do the test. It would probably be more effective to help health workers understand the effect of non-adherence than it would be to monitor it. Research should focus on which training strategies are most effective for this purpose.

Research is needed in certain grey areas. Lubell and colleagues' results were most sensitive to the value attributed to life cost (the value of a year of life lost), so if mortality is underestimated or overestimated the conclusions could partly change. However, mortality from malaria could be much lower than estimated-on the basis of previous reports and expert opinion-for patients with false negative rapid diagnostic test results who are not treated. This is because false negative results tend to occur in patients who have a very low parasite density and probably a low risk of mortality. ${ }^{10}$

A cohort study in Uganda found almost no risk of mortality for untreated patients who had false negative results on microscopy. ${ }^{11}$ If the same proves true for rapid diagnostic tests, this will provide more evidence to support adherence to the test result. Another grey area concerns the specificity of rapid diagnostic tests. Patients with a false positive malaria test may not be treated for the true cause of their fever. The high specificity of rapid diagnostic tests $(96 \%)$ found by Lubell and colleagues makes this risk marginal. Nevertheless, in endemic areas malaria parasites in the blood may be common in the general population-malaria infection in patients with fever may not necessarily be proof of clinical malaria. ${ }^{12}$ Some "true" positive patients (febrile patients with a positive rapid diagnostic test result confirmed by microscopy) may simply be carriers of malaria parasites, with another cause of fever. The potential harm from failure to treat, including mortality and related costs, may thus be underestimated. Future research focusing on the sensitivity and specificity of rapid diagnostic tests for clinical malaria-not just for malaria infection-would therefore be useful, although the study design may prove complex.

More data are also necessary from settings where the intensity of malaria transmission is variable over the seasons. Lubell and colleagues show that even an optimal adherence strategy based on treatment according to test results is not beneficial when transmission is high. In such circumstances it would be difficult to translate research findings into evidence based policy that is applicable throughout the year.

1 Lubell Y, Reyburn H, Mbakilwa H, Mwangi R, Chonya S, Whitty C, et al. The impact of response to the results of diagnostic tests for malaria: cost-benefit analysis. BMJ 2007 doi: 10.1136/ bmj.39395.696065.47.

2 WHO. Assessing RDT cost-effectiveness. 2007. www.wpro.who.int/ sites/rdt/Assessing+RDT+Cost-Effectiveness.htm.

3 Rolland E, Checchi F, Pinoges L, Balkan S, Guthmann JP, Guerin PJ. Operational response to malaria epidemics: are rapid diagnostic tests cost-effective? Trop Med Int Health 2006;11:398-408.

4 Rafael ME, Taylor T, Magill A, Lim YW, Girosi F, Allan R. Reducing the burden of childhood malaria in Africa: the role of improved diagnostics. Nature 2006;444(suppl 1):39-48.

5 Reyburn H, Mbakilwa H, Mwangi R, Mwerinde O, Olomi R, Drakeley C, et al. Rapid diagnostic tests compared with malaria microscopy for guiding outpatient treatment of febrile illness in Tanzania: randomised trial. $B M /$ 2007;334:403.

6 Hamer DH, Ndhlovu M, Zurovac D, Fox M, Yeboah-Antwi K, Chanda P, et al. Improved diagnostic testing and malaria treatment practices in Zambia. JAMA 2007;297:2227-31.

7 Van den Ende J, Lodesani C, Angheben A, Halidou T, Sirima SB, Van den Ende K, et al. Does the introduction of malaria antigen tests improve clinical care? Results from a randomized study in Burkina Faso. Trop Med Int Health 2007;12(s1):128.

8 Bassand J-P, Priori S, Tendera M. Evidence-based vs. "impressionist" medicine: how best to implement guidelines. Eur HeartJ 2005;26:1155-8.

9 D’Acrémont V, Lengeler C, Genton B. Stop ambiguous messages on malaria diagnosis BMJ 2007;334:489.

10 Hawkes M, Kain KC. Advances in malaria diagnosis. Expert Rev Anti Infect Ther 2007;5:485-95.

11 Njama-Meya D, Clark TD, Nzarubara B, Staedke S, Kamya MR, Dorsey $\mathrm{G}$. Treatment of malaria restricted to laboratory-confirmed cases: prospective cohort study in Ugandan children. Malar / 2007;6:7-15.

12 Schellenberg JRM, Smith T, Alonso PL, Hayes RJ. What is clinical malaria? Finding case definitions for field research in highly endemic areas. Parasitol Today 1994;10:439-42.

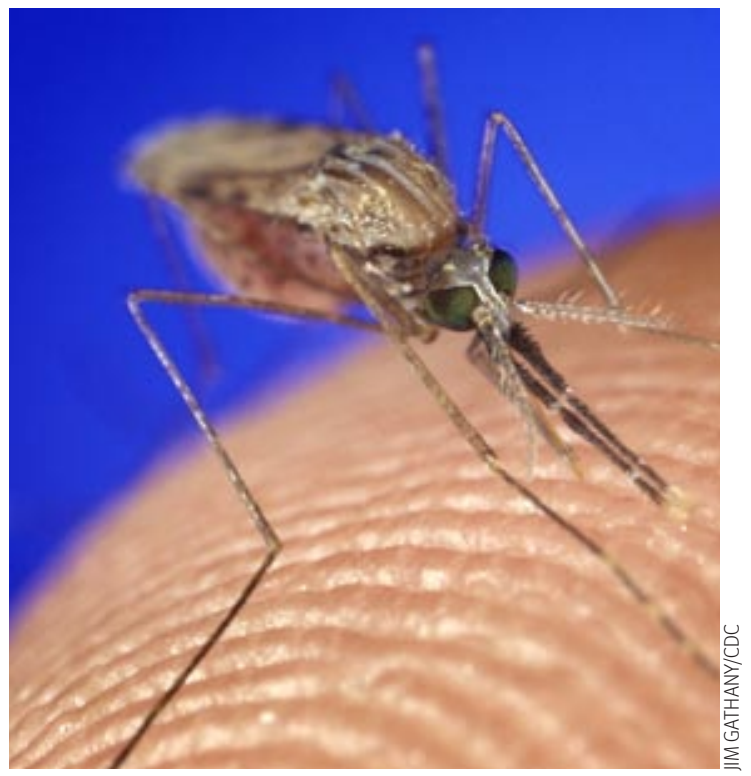

Anopheles gambiae mosquito 


\section{Mandatory disclosure of trial results for drugs and devices \\ New US law will require public posting of all the main results and data on harms}

\section{NEWS, p 180 \\ SHORT CUTS, p 182}

Trish Groves deputy editor, BMJ,

London WC1H 9JR

tgroves@bmj.com

Competing interest: TG is the

$B M$ J's senior research editor, whose remit includes encouraging authors to submit research to the $B M$ J.

Peer review and provenance: Not commissioned; not externally peer reviewed.

BMJ 2008;336:170 doi: 10.1136/bmi.39469.465139.80
Last week the drug industry was shown, twice, to have suppressed trial results that were commercially unfavourable-an all too familiar tale. ${ }^{12}$ But from September 2008, a new US law will mandate the public disclosure of such results, and it will no longer be left to investigative journalists and other researchers to dig out the findings of trials.

The FDA Amendments Act, passed quietly last year, rules that any ongoing clinical trial involving a drug, biological product, or device regulated by the US Food and Drug Administration (FDA) must be registered at clinicaltrials.gov and that, from 27 September 2008, triallists must start to post in that same registry the results of those trials. ${ }^{3}$ This applies to all clinical trials of drugs and devices except phase I drug trials (preliminary safety studies for new products) and small feasibility studies of a device. Furthermore, it covers all trials-whether or not they are conducted and sponsored by industry and wherever they are conducted-if the products concerned need approval by the FDA.

This law provides much needed enforcement. "Responsible parties" (sponsors or principal investigators of trials) who fail to comply will be fined $\$ 10000$ (£5100; €6900) for each infringement, with no upper limit, and they will be publicly named and shamed in non-compliance notices posted on clinicaltrials.gov. Moreover, triallists will not be able to drag their feet-the FDA requires disclosure of the results within one year of the date that "the last subject was examined or received intervention for purposes of final collection of data for the primary outcome." Although the act allows for delayed disclosure of results in exceptional circumstances, for instance in the interests of national security, it does not mention delay while awaiting publication in a peer reviewed journal. Will editors count such disclosure as prior publication and refuse to consider such trials for publication in their journals?

\section{Medical journals' current policies}

Urged on by the International Committee of Medical Journal Editors (ICMJE), many journals including the $B M J$ now consider clinical trials for publication only if they have already been registered. Taking this a step further, the ICMJE also ruled last summer that its member journals would consider trials whose results had been disclosed at a registry, as long as no more than one table of results or an abstract of up to 500 words had been made available to the public. ${ }^{4}$ The architects of the Ottawa statement on trial registration (http://ottawagroup.ohri.ca/) and the World Health Organization's international clinical trials registration platform (www.who.int/ictrp/en/) have called for fuller disclosure, but they have assumed that this would occur after publication in a peer reviewed journal. Yet the FDA has now mandated release of much more information, and this poses quite a challenge for editors and researchers. From September 2007, responsible parties for eligible trials must post on clinicaltrials.gov two tables giving all the key results for the main outcomes, and from next year they must post two tables of any harms reported during the trial. Further public consultations in 2009 may lead to further expanded disclosure under the act.

\section{What should journals do now?}

The $B M J$ will consider disclosed trials and urges other journals to do the same for several reasons. Firstly, disclosure will be a legal requirement, so there is nothing editors can do about it if they still want to publish important trials of drugs and devices. Moreover, journals will continue to add value by publishing useful and readable trial reports that clinicians, the media, and patients can interpret and use. And, most importantly, the results disclosed for the FDA will not have been externally peer reviewed and will be preliminary. Peer review not only provides a stamp of quality assurance, it often leads to reanalysis of results.

Two challenges remain. Will a journal still want to publish a paper if its results have been posted on clinicaltrials.gov; if they have been debated widely in the mass media along with quotes from respected clinical experts, and-as is often the case-if they have led to a widely publicised rise or fall in the share price of the company that sponsored the trial? And, in the long run, will the role of peer reviewers and medical journals as the gatekeepers of new medical evidence become redundant?

At the $B M J$ we support this great leap forward for public disclosure. And, if you have an important and robust trial of a drug or device that you would like published before disclosing the results on clinicaltrials.gov, contact us early and request fast track review. We do not plan to turn down trials that have already been disclosed, but-through rapid open access publication-we can get the full peer reviewed work into the public domain quickly on bmj.com and, where the results are important, we are keen to do so.

1 Schering-Plough Press Release. Merck/Schering-Plough Pharmaceuticals provides results of the ENHANCE trial. 2008. www.schering-plough.com/schering_plough/news/release. isp?releaselD=1095943.

2 Turner EH, Matthews AM, Linardatos E, Tell RA, Rosenthal R. Selective publication of antidepressant trials and its influence on apparent efficacy. N Engl / Med 2008;358:252-60.

3 US Food and Drug Administration. Law strengthens FDA. 2007. www.fda.gov/oc/initiatives/advance/fdaaa.html.

4 Laine C, Horton R, DeAngelis CD, Drazen JM, Frizelle FA, Godlee F, et al. Clinical trial registration. BMJ 2007;334:1177-8. 